\title{
Fabrication of flexible nanostructured silver-polymer films for sensors and bio-warfare or bacterial treatment and conducting gold-silver-polymer film for flexible electronics
}

\author{
Syeda Khurshida Begum a,b \\ a Department of Chemistry, University of Chittagong, Chittagong 4331, Bangladesh \\ b Department of Chemistry, State University of New York at Binghamton, NY 13902, USA \\ *Corresponding author at: Department of Chemistry, University of Chittagong, Chittagong 4331, Bangladesh. \\ Tel.: +88.018.30034350. Fax: +88.031.726310. E-mail address: syedacu@gmail.com (S.K. Begum).
}

\section{ARTICLE INFORMATION}

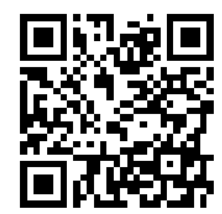

DOI: 10.5155/eurjchem.5.4.618-627.1089

Received: 08 May 2014

Accepted: 31 May 2014

Online: 31 December 2014

\section{KEYWORDS}

Flexible electronic

Conducting polymer

Anti-bacterial activity

Anti-bio-warfare agent

Nanostructured polymer

Metal-polymer composite

\section{Introduction}

Advanced technology desires miniaturization. New products seek more compact packing, savings in space, savings in weight, and cost savings in production. Flexible and conductive or conducting polymer film could support this demand by substituting the rigid electronic circuit. Metallization of polymers could be the way of making polymer film conductive. For practical applications, the flexible conductive film is expected to be mechanically strong enough with good metal-polymer adhesion. However, printing of electronic circuit on polymers for flexible electronics is a challenging attempt as there is no strong interaction between metal particles like $\mathrm{Ag}, \mathrm{Au}, \mathrm{Ni}$ and $\mathrm{Cu}$ with polymers [1]. Different practical issues such as diffusion, interfacial reactivity, weak metal-polymer adhesion, blistering /metalmetal complex in metal-metal interface, weak mechanical properties of resulting metal-polymer film hinder success of metallization of polymer film [2,3]. Consequently, though metalized polymer films have been the interest of research for decades, and highly reflective or/and conductive flexible polymer films have been obtained via different multi-step or single-step synthesis methods [4-11], synthesis of flexible, electrically conductive polymer film with good mechanical strength, and metal-polymer adhesion by a simple and costeffective method has not been observed yet.

On the other hand, metal nanomaterials such as nanoparticles, nanotubes and nanofibers, show extraordinary electrical, optical, chemical and magnetic properties, different from the bulk [12-16]. To utilize the size and shape dependent brilliant properties, the nanomaterials need to be stabilized in the nanometer range. Thin polymer film is considered as a convenient matrix to use for this purpose [17]. Hence nanostructured metal-polymer films involving different metals such as $\mathrm{Au}, \mathrm{Cu}$ and $\mathrm{Ag}$ have been the growing interest of research [18-24]. Amongst them silver nanowires-polymer have drawn a special attention due to their high mechanical flexibility and low sheet resistance [25]. Carbon based nanomaterial-polymer films have also been extensively studied since carbon nanomaterials also demonstrate some excellent mechanical and electrical properties [26-29]. Nanostructured materials also have drawn a great deal of attention due to their potential for achieving specific processes and selectivity, especially in biological and pharmaceutical applications $[30,31]$. Unfortunately, the fabrication processes of nanofibers or nanotubes are often costly and complicated. Among nanomaterials, silver nanoparticles have antibacterial or antibio-warfare activities [32-35], thus Ag nanoparticle-polymers 


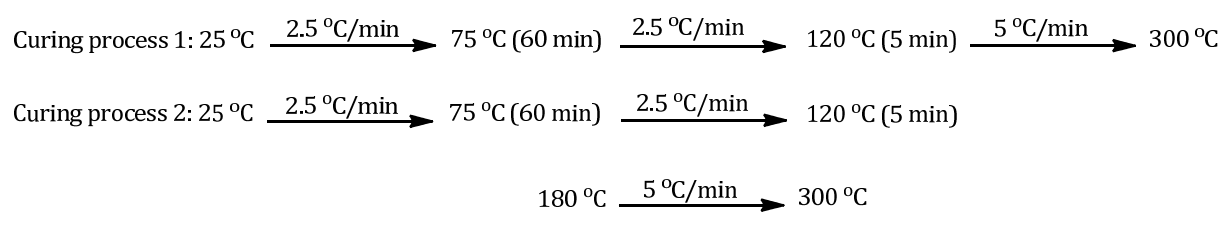

Scheme 1

have been an emerging field of research [36-40]. Flexibility of such polymer films can extend their application to a wider range [17]. However, a large scale production and commercialization of nanocomposites is still a key challenge because of lack of cost-effective, simple synthesis method [17].

Hence, this study has been carried out for synthesis of: $i$ ) strong flexible Ag nanoparticle-polymer film with strong Agpolymer adhesion via a simple, convenient, cost-effective synthesis route and ii) conductive polymer film with a good combination of flexibility, mechanical strength and metalpolymer adhesion utilizing the simple method. Here, the strategy was to get flexible, strong, thermally stable $\mathrm{Ag}$ nanoparticle-polymer/Ag-polymer film with high load of Ag and good Ag-polymer adhesion by one-step synthesis method through studying the effect of $\mathrm{Ag}^{+}$concentration and different curing processes and perform electroless plating of $\mathrm{Au}$ on the selected strong flexible Ag-polymer film to obtain conductive $\mathrm{Au}$-Ag-polymer film. For electroless plating, Au was chosen considering wide application of $\mathrm{Au}$ in printing electronic circuits [41-44]. While most of the previous studies on Agpolymer or Au-polymer film focused on 'reflective and/or conductive' film or 'nanostructured' or 'flexible film', the focus of this study was on the factors: $i$ ) flexible and mechanically strong film; ii) good metal-polymer adhesion in the film; iii) a simple cost-effective synthesis method and $i v$ ) high load of metal particles in the nanostructured polymer film (for sensors or for anti-bacterial/anti-bio-warfare applications) or in the conductive polymer film (for flexible electronic) which, altogether are necessary for practical applications of such flexible films but has not been reported yet.

\section{Experimental}

\subsection{Materials}

3,3'4,4'-Benzophenone tetracarboxylic dianhydride (BTDA), 4,4'-oxydianiline (4,4' ODA) were used as carboxylic acid and amine, respectively, in this synthesis process. $N, N$ Dimethylacetamide (DMAc) was used as solvent. Silver(I) acetate was used as a source of silver. 1,1,1-Trifluoro-2,4pentanedione (TFAH) was used to make a soluble Ag complex [6,7]. For electroless plating of gold, gold (cyanide) solution was used. Borane dimethyl amine (DMAB) was used as a reducing agent in the plating bath. All the reagents were analytical grade and purchased from Sigma-Aldrich and were used as supplied. A Fisher Scientific isotemp programmable force-draft muffle furnace (Series 750, Model 126) was used for thermal curing.

\subsection{Synthesis of polymer}

For synthesis of polymer or polyimide (PI) different compositions of amine (BTDA), carboxylic acid (ODA), and solvent (DMAc) were used. It was found that optimum composition of the amine, carboxylic acid, and solvent is 0.2329 $\mathrm{g}$ of BTDA and $0.1425 \mathrm{~g}$ of ODA in $2.5 \mathrm{~mL}$ of DMAc. Initially, solid BTDA and ODA were mixed well, then DMAc was added with constant shaking of the mixture. The resulting yellow colored polyamic acid (PAA) solution was stirred for about two hours using a magnetic stirrer. PAA solution was then poured onto a petri dish to make a thin film. Stability of the petri dish was checked earlier in the furnace up to the highest experimental temperature $300{ }^{\circ} \mathrm{C}$ and appeared stable at this temperature range. The petri dish with the thin layer of PAA solution was immediately put in the furnace. After 15 minutes at room temperature in the oven the film was started to cure. Two different curing processes as process 1 and process 2 were used for curing the PI film. In process 1 , the furnace temperature was increased from 25 to $75^{\circ} \mathrm{C}$ with a rate of increase of temperature $2.5^{\circ} \mathrm{C}$ per minute, kept at $75^{\circ} \mathrm{C}$ for 60 minutes, then temperature was increased to $120{ }^{\circ} \mathrm{C}$ with a rate of increase of temperature $2.5{ }^{\circ} \mathrm{C}$ per minute, kept at that temperature for 5 minutes, and then increased temperature to $300{ }^{\circ} \mathrm{C}$ with a rate of increase of temperature $5{ }^{\circ} \mathrm{C}$ per minute. In process 2 , the furnace temperature was programmed as in curing process 1 , but the difference here is that instead of continuous heating in the furnace the petri dish with the film was taken out from the furnace after 5 minutes of reaching the temperature to $120{ }^{\circ} \mathrm{C}$, the film was detached from the petri dish after cooling, then put back in the furnace when the temperature reached to about $180^{\circ} \mathrm{C}$, continued heating in the furnace as per programmed temperature. Process 1 and 2 can be expressed in Scheme 1.

\subsection{Synthesis of Ag-polymer film}

In Ag-PI synthesis, different amount of silver acetate in DMAc and TFAH were added to PAA solution to get 5, 10 and $20 \%$ silver in cured Ag-PI film. As silver acetate is insoluble in PAA solution, TFAH was used to make it soluble in the PAA solution [4]. The way of mixing of the components was found to be important in getting a good Ag-polymer film as was found in the case of synthesis of PI. To make the mixture of AgAc, DMAc and TFAH, initially DMAc was added to silver acetate, shook well, then TFAH was added drop by drop, after addition of each drop of TFAH shaking the mixture very well. The mixture was then added to the previously prepared PAA solution. Here, TFAH forming a AgTFA soluble complex favor the formation of Ag-polymer at a high temperature [6,7]. For 5, 10 and 20\% silver in the polymer film, $0.015,0.03$ and $0.06 \mathrm{~g}$ of silver acetate and 2, 4 and 8 drops of TFAH were used respectively in the Ag-PAA solutions.

After mixing and stirring for about 15 minutes at $25{ }^{\circ} \mathrm{C}$ and 15 minutes at $50{ }^{\circ} \mathrm{C}$ clear solutions were obtained for all the three different silver concentrations. A magnetic stirrer was used to stir the mixtures. The mixtures were then poured onto a petri dish and immediately put in the oven. After 15 minutes the mixtures were started to cure in the oven using curing process 1 and 2. Additionally three other curing processes as curing process 3,4 and 5 were used in curing the Ag-PI film. The processes can be expressed in Scheme 2.

Percent silver was calculated roughly, assuming existence of only silver and polymer in the cured film. Schematic of AgPolymer film synthesis has been presented in Figure 1.

\subsection{Electroless Au plating on Ag-polymer film}

Successful gold plating on flexible substrate is expected to provide flexible electronic circuit thus tested on polyimide by different methods as laser assisted deposition method [6] and electroless plating [45] after surface modification. 


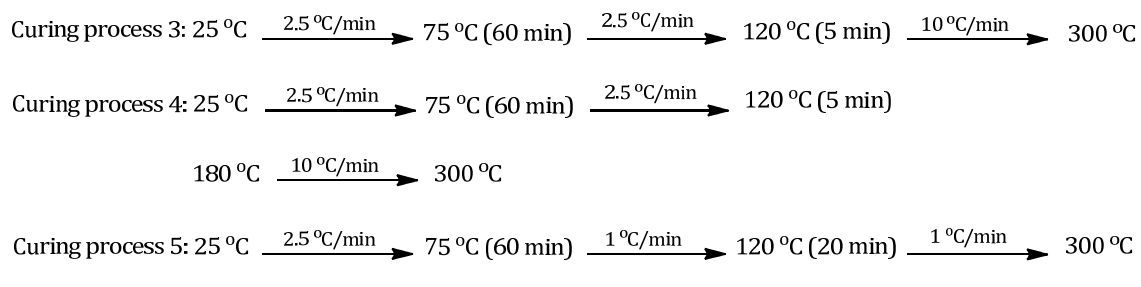

Scheme 2

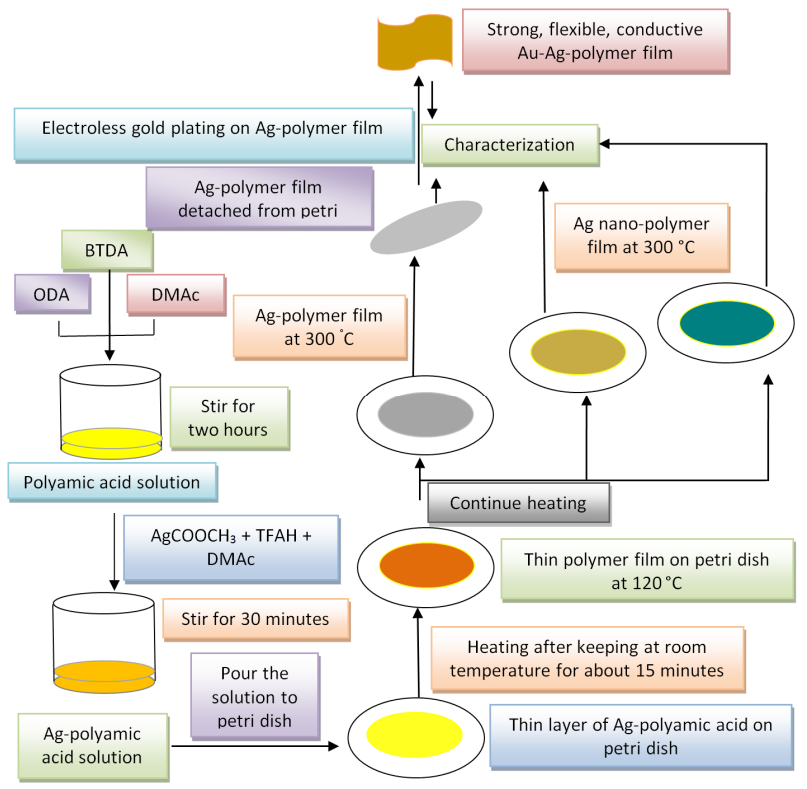

Figure 1. Schematic of synthesis of strong, flexible, nanostructured Ag-polymer and conductive gold-silver-polymer film.

However, the methods resulted in $\mathrm{Au}$-PI film with weak $\mathrm{Au}$ PI adhesion or/and weak polymer film. In this study Au was electrolessly plated on the synthesized Ag-polymer film. Plating condition was optimized for this purpose varying the amount of DMAB in gold (cyanide) solution and varying the temperature. $0.145 \mathrm{~g}$ of DMAB in $50 \mathrm{~mL}$ gold (cyanide) solution at $25^{\circ} \mathrm{C}$ was found as optimum plating condition. For successful plating of $\mathrm{Au}$ on Ag-polymer film, the plating bath was set at $25^{\circ} \mathrm{C}$ on a magnetic stirrer and a piece of Ag-polymer film was suspended into the gold solution. DMAB was then added slowly to the solution. The polymer film was taken out from the plating bath after two hours. Au plating was conducted two times on the same Ag-polymer film. Schematic of Au-Ag-polymer film synthesis has been presented in Figure 1.

\subsection{Film characterization}

Selected metal-polymer films, which were found significant for practical applications in terms of mechanical strength, were characterized by Scanning Electron Microscopy (SEM) and Electron Dispersion Spectroscopy (EDS) to comprehend their surface morphology. SEM was recorded at 10,000 times and in some cases at 40,000 times magnification. Mechanical strength of the films was tested by measuring modulus of the films with a Dynamic Mechanical Analyzer (DMA Q-800). Prophilometer was used to measure the film thickness. Adhesion was tested by conventional method (ASTM) using an adhesive tape. Surface resistivity of the films was measured with a four point probe. Electrochemical characterization was performed by cyclic voltammetry. Photographs of selected films and their SEM and EDS images have been presented in Figures 2-12.

\section{Results and discussion}

\subsection{Synthesis of polymer film}

In the curing process 1 and 2 strong flexible polymer film at $300{ }^{\circ} \mathrm{C}$ as shown in Figure 2 named as Film B was obtained. Modulus of the film was found to be around $2.58 \mathrm{GPa}$, which is near the modulus of most of the commercial polyimide films [46]. At high temperature $300^{\circ} \mathrm{C}$, carboxylic groups of PAA lose water and convert to imide group thereby form polyimide (PI) $[7,8,47,48]$. Structure of polyimide obtained from polyamic acid [4] has been represented in Scheme 3 [7].

\subsection{Synthesis of silver-polymer films}

At high temperature, during imidization of PAA to PI, it is expected that $\mathrm{Ag}^{+}$in PAA are simultaneously reduced to $\mathrm{Ag}$, thereby form Ag-PI film [4,7]. In this experiment it was experienced that in one-step method, brittleness of the metalized polymer film at $300{ }^{\circ} \mathrm{C}$, was the major problem in obtaining Ag-polymer film mechanically strong enough for practical application, whereas the multi-step vapor deposition method and laser-assisted deposition method [5,6] faced the problem of weak metal-polymer adhesion and/or brittleness of the metalized polymer films. In this study it was apparent that mechanical strength, color, conductivity and Ag-polymer adhesion of the film varied with variation of silver concentration and curing process. 


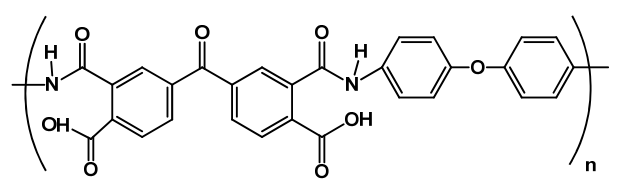

BTDA/ODA poly(amic acid) form

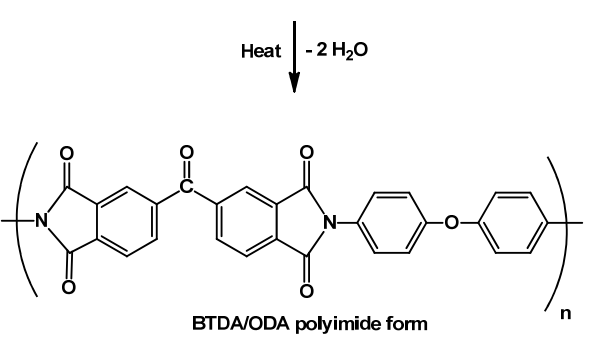

Scheme 3
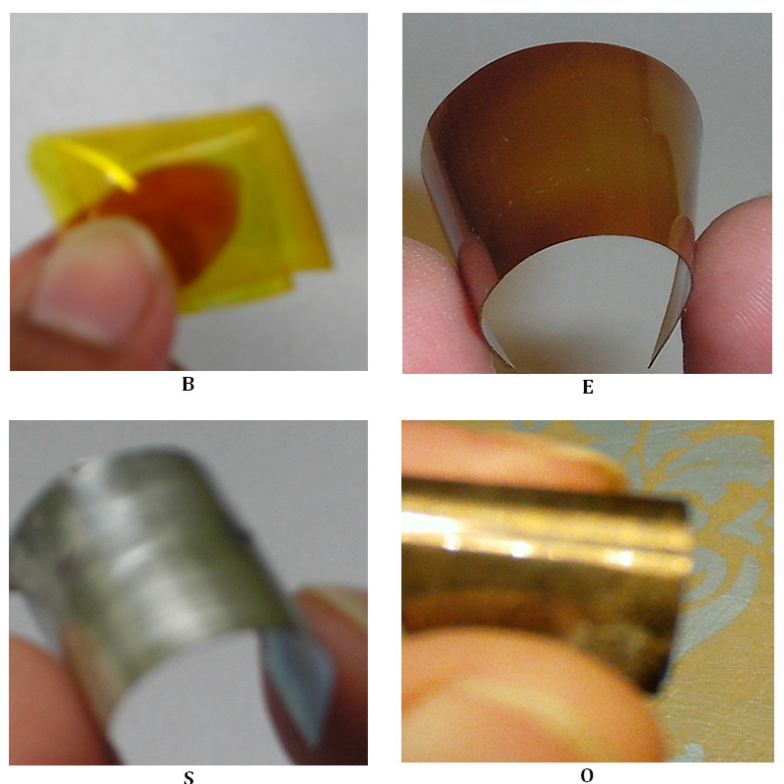

Figure 2. Photographs of the synthesized mechanically strong, flexible polymer films; a) Polyimide at $300{ }^{\circ} \mathrm{C}$ (Film B); b) Ag-polymer film at $120{ }^{\circ} \mathrm{C}$ (Film E); c) Ag-polymer film with excellent Ag-polymer adhesion obtained at $300^{\circ} \mathrm{C}$ (Film S) and d) Conductive Au-Ag-polymer film (Film 0) obtained by electroless plating of Au on Film S.

The experimental results at $300{ }^{\circ} \mathrm{C}$ for different silver concentrations and different curing processes have been listed in Table 1.

For the same curing process, mechanical strength of the Agpolymer film appeared to decrease with the increase of $\mathrm{Ag}^{+}$ concentration in PAA solution. For instance, curing process 4 produced strong Ag-polymer film (Film 4) for 5\% silver, whereas it produced a very weak film (Film 14) for $20 \%$ silver. By curing process 5, silver colored Ag-polymer film with modulus of $1.85 \mathrm{GPa}$ (Film 10) was obtained for low concentration as $10 \%$ silver at $300{ }^{\circ} \mathrm{C}$; however, for the same experimental condition for $20 \%$ silver the film (Film 15) was degraded. A high concentration of $\mathrm{Ag}^{+}$might decreases the efficiency of imidization process at higher temperature. Consequently, the polymer film became brittle and degraded. In support of this explanation, it is seen that by examining the chemical states of selected elements in the synthesized Ag-PI film of $300^{\circ} \mathrm{C}$ with X-ray Photoelectron Spectra (XPS), Rubira et al. [4] found two kinds of nitrogen species in the film. This is an indication of incomplete imidization. According to them the strong interaction between silver and carboxylic acid group probably leads to incomplete imidization.

Higher concentration of Ag-salt in PAA solution and higher rate of increase of temperature during curing process favored the formation of conductive Ag-polymer film. Flexible, weak, conductive Ag-polymer film with surface resistivity of 3.62 $\Omega /$ Sq (Film 14) was obtained for $20 \%$ silver by curing process 4. A possible explanation of this observation might be that conductivity of the film arose when there were sufficient amount of reduced Ag particles on the film surface.

It was found that in the same curing process, at $300{ }^{\circ} \mathrm{C}$, color of the cured film was depended on the total silver concentration. In curing process 5 golden colored film as shown in Figure 3 (Film H) was obtained for 5\% silver and silver colored film as shown in Figure 2 (Film S) was obtained for $10 \%$ silver. In curing process 4 blue colored film (Film L, Figure 3) was generated for $5 \%$ silver, whereas silver colored film (Film K) was generated for $10 \%$ silver. 
Table 1. Summary of experimental results for synthesis of Ag-polymer films at $300^{\circ} \mathrm{C}$.

\begin{tabular}{|c|c|c|c|c|c|}
\hline \multirow[t]{2}{*}{ Curing process } & \multicolumn{3}{|c|}{ Appearance ${ }^{c}$} & \multirow[t]{2}{*}{ Modulus GPa ${ }^{f}$} & \multirow[t]{2}{*}{ Film no./Name g } \\
\hline & Surface color & Mechanical strength & Adhesion & & \\
\hline \multicolumn{6}{|c|}{ 5\% Silver in Ag-PI film } \\
\hline 1 & Golden & Weak & Strong & NM & 1 \\
\hline 2 & Brown & Strong b & Strong & 2.16 a & 2 \\
\hline 3 & Golden & Weak & Strong & NM & 3 \\
\hline 4 & Blue & Strong b & Strong & 1.75 a & 4 (Film L in Figure 3) \\
\hline 5 & Golden & Strong $\mathrm{b}$ & Strong & $1.84 \mathrm{a}$ & 5 (Film $\mathrm{H}$ in Figure 3 ) \\
\hline \multicolumn{6}{|c|}{ 10\% Silver in Ag-PI film } \\
\hline 1 & Silver & Weak & Strong & NM & 6 \\
\hline 2 & Bright Golden & Strong b & Strong & 1.92 a & 7 (Film G in Figure 11) \\
\hline 3 & Silver & Weak & Weak & NM & 8 \\
\hline 4 & Silver & Strong $\mathrm{b}$ & Strong & $1.41^{\text {a }}$ & 9 (Film K in Figure 9) \\
\hline 5 & Silver & Strong $\mathrm{b}$ & Strong & 1.48 a & $10^{\mathrm{d}}$ (Film S in Figure 2) \\
\hline \multicolumn{6}{|c|}{$20 \%$ Silver in $\mathrm{Ag}-\mathrm{PI}$ film } \\
\hline 1 & Silver & Degraded film & NA & NA & 11 \\
\hline 2 & Silver & Weak & Strong & NM & 12 \\
\hline 3 & Silver & Degraded film & NA & NA & 13 \\
\hline 4 & Silver & Weak e & NA & NA & 14 \\
\hline 5 & Silver & Degraded film & $\mathrm{NA}$ & NM & 15 \\
\hline
\end{tabular}

a Modulus was measured only for those films which were apparently significant for practical applications.

b All strong films were flexible and qualitative idea on flexibility was obtained by bending the films as shown in Figure 2 and 3.

cAir side of the films (on petri dish) were considered for expressing color, Ag-polymer-adhesion and conductivity.

$\mathrm{d}$ This mechanically strong film with thickness of $80 \mu \mathrm{m}$ was selected for Au plating because of high load of Ag particles on the film surface.

e This film was conductive with surface resistivity of $3.62 \Omega / \mathrm{Sq}$

f NM = Not measured, NA = Not applicable.

g Film $\mathrm{E}$ is not included in this table as it was at low temperature $120^{\circ} \mathrm{C}$.
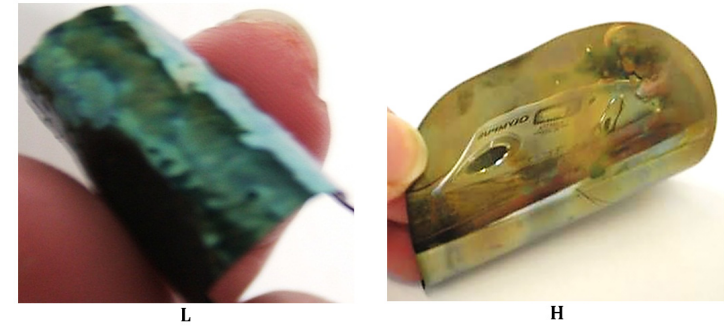

Figure 3. Photographs of the nanostructured, mechanically strong, flexible Ag-polymer films with excellent Ag-polymer adhesion obtained at $300^{\circ} \mathrm{C}$ for $5 \%$ silver a) Blue colored film obtained by curing process 4 (Film L) b) Golden colored film obtained by curing process 5 (Film H).
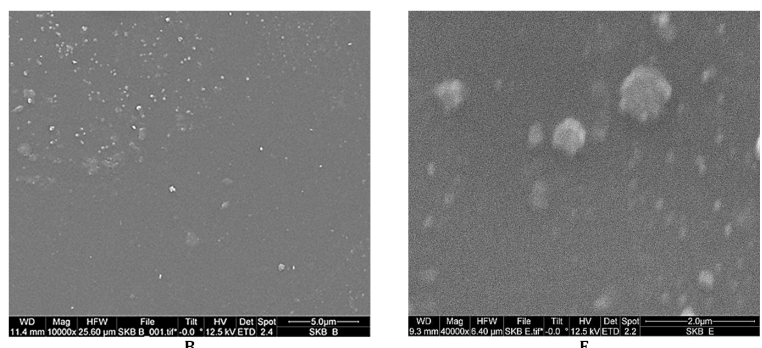

Figure 4. SEM of mechanically strong polymer films a) Polyimide at $300{ }^{\circ} \mathrm{C}$ (Film B) b) Ag-polymer film at $120^{\circ} \mathrm{C}$ (Film E).

In curing process 2, bright golden colored film (Film G, Figure 11) was obtained for $10 \%$ silver whereas silver colored weak film (Film 12) was obtained for $20 \%$ silver.

For the same concentration of $\mathrm{Ag}^{+}$in PAA solution, Agpolymer film appeared stronger for a lower rate of increase of temperature during the curing process. Flexible, strong, nonconductive, silver colored Ag-polymer film (Film S) with excellent Ag-polymer adhesion and modulus data $1.48 \mathrm{Gpa}$ was obtained for $10 \%$ silver by slow curing process (process 5), whereas for the same silver concentration fast curing process (process 3) generated silver colored weak Ag-polymer film (Film 8).

Ag-polymer adhesion was found to be greatly affected by the rate of increase of temperature during curing process. While slow curing process (process 5) generated Ag-polymer film with excellent Ag-polymer adhesion for $10 \%$ silver (Film S, Figure 2), for the same Ag concentration fast curing process (process 3) generated Ag-polymer film with weak Ag-polymer adhesion (Film 8).
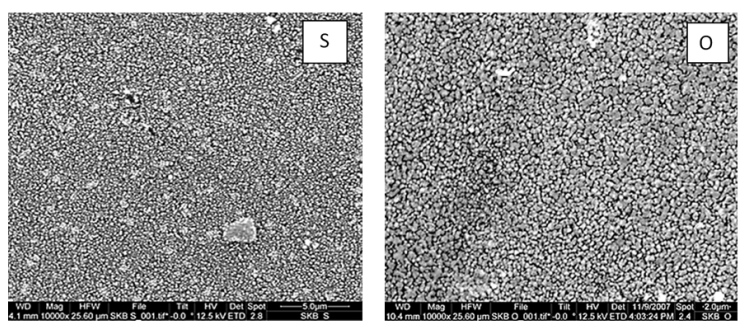

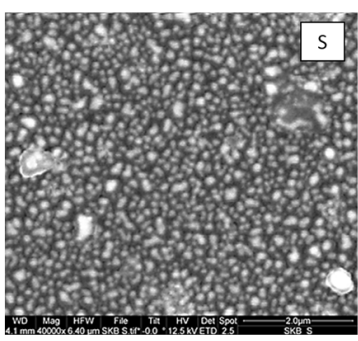

(a) Ag-polymer film

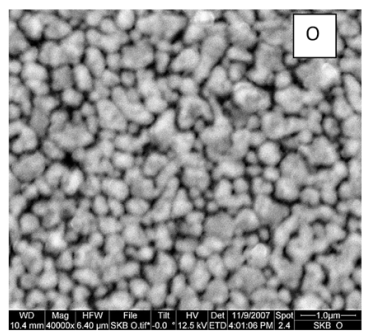

(b) Au-Ag-polymer film
Figure 5. SEM of films a) Ag-polymer film (Film S) and b) Conductive Au-Agpolymer film (Film 0 ) obtained by electroless plating of $\mathrm{Au}$ on Film S, at two different magnifications, 10,000X (Top) and 40,000 X (Bottom). Images show high load of metal particles on the Film S surface. Metal load is seen much higher in the gold plated Ag-polymer film surface (Film O) than on film Agpolymer film (Film S).

Curing type, whether continuous or noncontinuous, was also found to be a factor in film strength or/and silver reduction in the polymer film. For instance, for $10 \%$ silver continuous heating (curing process 1 ) generated silver colored weak film (Film 6), whereas for the same silver concentration noncontinuous heating (curing process 2) generated bright golden colored strong film (Film G, Figure 11). For 5\% silver it was found that continuous heating (curing process 1) generated weak golden colored film (Film 1) while noncontinuous heating (curing process 2) generated mechanically strong, brown colored film (Film 2). 


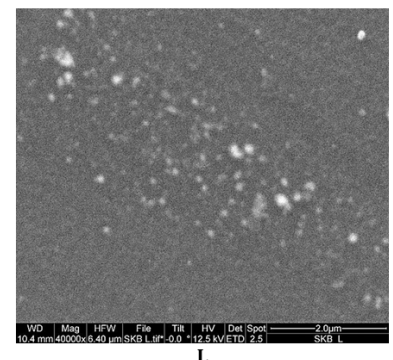

L

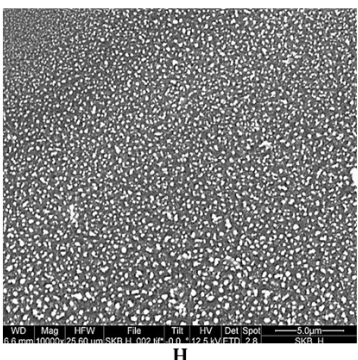

$\mathbf{H}$

Figure 6. SEM of nanostructured, mechanically strong, flexible Ag-polymer films with excellent Ag-polymer adhesion obtained at $300{ }^{\circ} \mathrm{C}$ for $5 \%$ silver: a) Blue colored film obtained by curing process 4 (Film L); b) Golden colored film obtained by curing process 5 (Film H). Golden colored film shows almost uniform deposition of nano size metal particles on the surface and this metal load is seen much higher than on blue colored film.
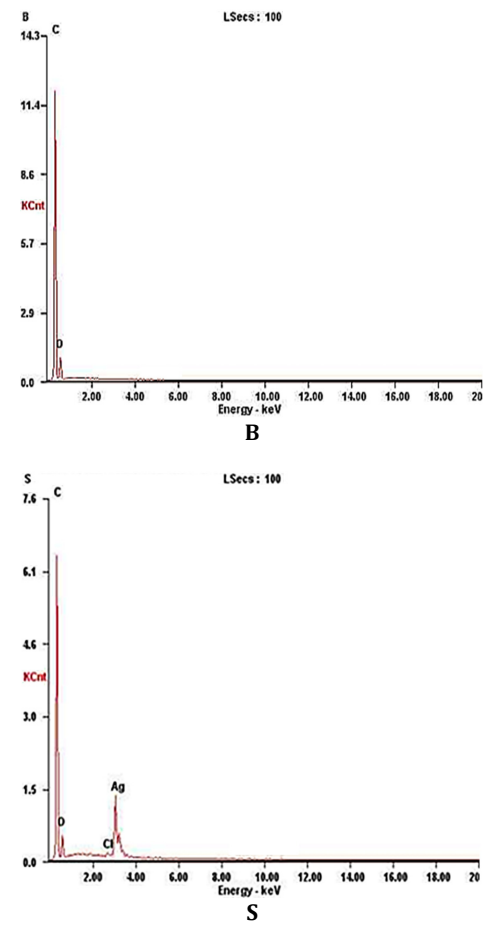
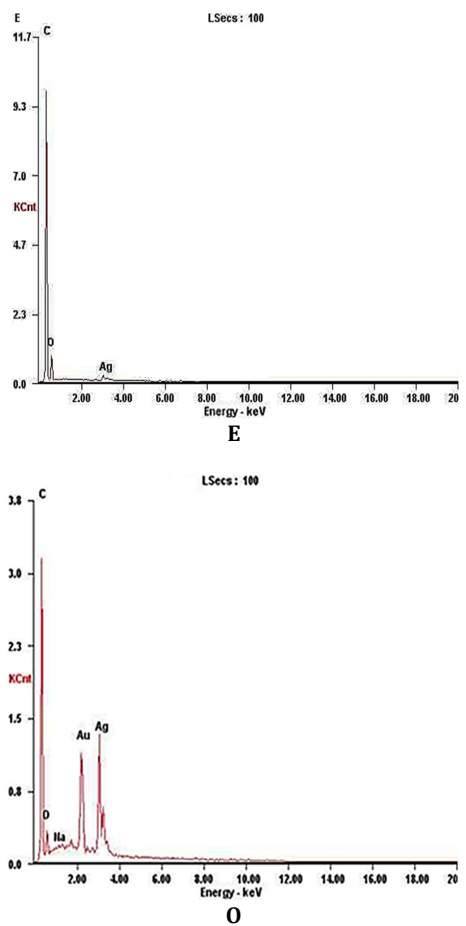

Figure 7. EDS of mechanically strong, flexible, polymer films: a) Polyimide at $300^{\circ} \mathrm{C}$ (Film B); b) Ag-polymer film at $120^{\circ} \mathrm{C}$ (Film E); c) Silver colored Ag-polymer film with excellent Ag-polymer adhesion obtained at $300^{\circ} \mathrm{C}$ (Film S); d) Conductive, golden colored Au-Ag-polymer film with excellent Au-Ag-polymer adhesion (Film 0) obtained by electroless plating of Au on Film S. Polyimide (Film B) shows no silver peak. Film E showing very weak peak of Ag indicates the presence of very few reduced silver on the film surface at that condition. Film S shows intense Ag peak indicating high load of reduced silver on the film surface. Golden colored Au-plated film (Film 0) shows intense gold peak indicating successful plating of gold on the Ag-polymer film.

It has been the general observation that lower $\mathrm{Ag}^{+}$ concentration in PAA solution, lower rate of increase of temperature during curing process (process 1, 2) and noncontinuous heating (process 2 and 4) favored the formation of strong nanostructured Ag-polymer film with strong Agpolymer adhesion, whereas higher $\mathrm{Ag}^{+}$concentration in PAA, continuous heating (curing process 1 and 3 ) and higher rate of increase of temperature (process 3 and 4) favored the formation of silver colored film or conductive Ag-polymer film but decreased mechanical strength of the polymer film.

Several other metal ions such as iron [49], gold [50] and copper [51] had been studied with polyamic acid and found to be reduced to the metal particles in polyamic acid medium as a result of heating to high temperature. Since the beginning of this one-step synthesis method, $\mathrm{Ag}^{+}$reduction during curing process at high temperature had been termed as thermal reduction while imidization occurs at the same time. Regarding this, recently it was reported that the mechanism of silver reduction and factors affecting silver aggregation and migration remain unclear up to now [9]. According to Southward et al. [8] thermal curing of the Ag(I)-polyamic acid film affects the reduction of $\mathrm{Ag}(\mathrm{I})$ coupled with imidization of the polyamic acid.

In silver-PAA solution there are free carboxyl groups as well as carboxyl groups bonded with $\mathrm{Ag}^{+}$. Silver ions bonded to carboxyl group prevent imidization [4]; thereby decrease the strength of cured Ag-polymer film. There is a possibility of oxidation of PAA to some extent by $\mathrm{Ag}^{+}$, depending on the $\mathrm{Ag}^{+}$ concentration in PAA, which also affects the strength of cured Ag-polymer film. $\mathrm{Ag}^{+}$in PAA has a tendency to accept electron from nitrogen in PAA, which is accelerated with increase of temperature because of increase of rate of reaction.

\subsection{Ag-polymer adhesion}

Adhesion between Ag particles and polymer film was tested by boiling the film in water and using adhesive tapes. 

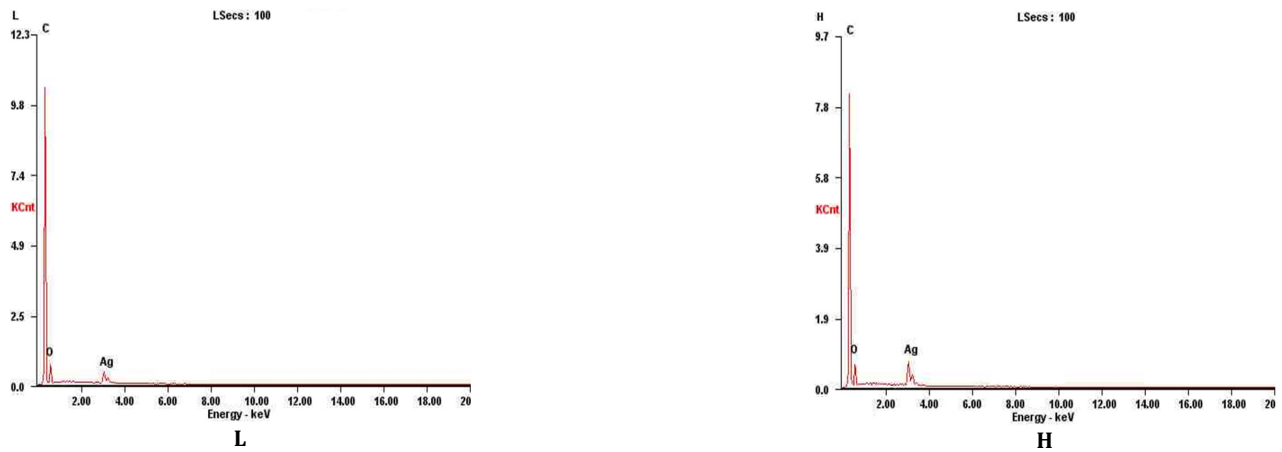

Figure 8. EDS of nanostructured, mechanically strong Ag-polymer films with excellent Ag-polymer adhesion obtained at $300{ }^{\circ} \mathrm{C}$ for $5 \%$ silver: a) Blue colored film obtained by curing process 4 (Film L); b) Golden colored film obtained by curing process 5 (Film H).
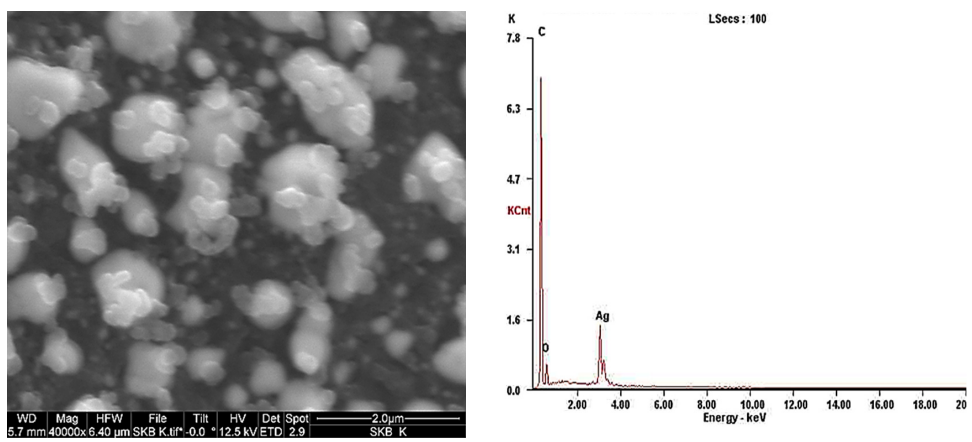

Figure 9. SEM and EDS images of silver colored $10 \%$ Ag-polymer film (Film K) obtained at $300{ }^{\circ} \mathrm{C}$ by curing process 4 .

For some films Ag-polymer adhesion was weak. But for most of the films Ag-polymer adhesion was found excellent. For the films S, L, H, G, K there was no apparent loss of Ag particles from the film surface after boiling with water and apparently no adhesive tape removed any silver from the surface as per the ASTM adhesion testing protocol which indicated excellent Ag-polymer adhesion in those films. During curing the Ag-PAA film, while $\mathrm{Ag}^{+}$is reduced to $\mathrm{Ag}$ and PAA converts to PI, depending on the curing process and total silver concentration, Ag particles take place in between the polymer network i.e. Ag particles are interlocked [9] in between large polymer molecules and result polymer films with strong Ag- polymer adhesion.

\subsection{SEM images and EDS spectra of the Ag-polymer films}

SEM (Figure 5) of Film S (silver colored $10 \%$ Ag-polymer film cured by curing process 5) shows high load of metal particles on the film surface. Intense peak of Ag in EDS (Figure 7) of this film confirms high load of Ag particles on the film surface. Whereas no metal particles were observed in SEM (Figure 4) and EDS (Figure 7) for PI (Film B), metal particles observed in SEM image (Figure 4) and Ag peak in EDS image (Figure 7) of Film E (film obtained at $120{ }^{\circ} \mathrm{C}$ during curing process 5 for $10 \%$ Ag-polymer film) indicate that Ag reduction happened/started even at such low temperature though very few in magnitude. SEM (Figure 6) of Film L (blue colored 5\% Ag-PI film obtained by curing process 4 ) and Film $\mathrm{H}$ (golden colored $5 \%$ Ag-polymer film obtained by curing process 5 ) also show high load of metal particles and EDS (Figure 8) of these films show intense Ag peaks. SEM and EDS of Film G (bright golden colored $10 \%$ Ag-PI film obtained by curing process 2 ) in Figure 11 and film K (silver colored $10 \%$ Ag-polymer film obtained by curing process 4) in Figure 9 show high load of Ag particles on the film surfaces. Intensity of Ag peak in EDS is related to the amount of reduced silver (from $\mathrm{Ag}^{+}$) on the film surface. The more the reduced silver on the surface the higher the intensity of Ag peak. Comparing the EDS of the synthesized films it was found that at the same experimental condition, order of intensity of Ag peak of Film S (10\% silver) is higher than of Film H (5\% silver). For different colored films, in Figure 10 , it has been observed that the Ag peak intensity order is, silver color (Film K, Film S) > golden color (Film G, Film H) > blue color (Film L) > brown color (Film E). SEM images of the films also support this order.

Different colored surfaces of the Ag-polymer film might be related to the amount of reduced silver particles existing on the film surface as well as to the size of the particles on the surfaces as Ag particles, like other metal particles, show different colors depending on their size in the nanometer range [52].

\subsection{Au plated Ag-polymer film}

For electroless plating of Ag-polymer film by $\mathrm{Au}$, flexible, mechanically strong, Ag colored Ag-polymer film with high load of Ag on the surface and modulus of $1.48 \mathrm{GPa}$ with excellent Agpolymer adhesion was selected (Film S). Thickness of this film was $80 \mu \mathrm{m}$. Electroless gold plating of this film gave bright golden colored conductive Au-Ag-polymer film described here as Film 0. Surface resistivity for this film was found $2.6 \Omega / \mathrm{Sq}$. Modulus of the Au plated Ag-polymer film was not changed significantly because of this electroless deposition whereas expensive laser assisted deposition was found to produce weak metal-polymer film [6]. The experimental results for synthesis of Film $\mathrm{O}$ have been listed in Table 2. Conductive Au-Agpolymer film (Film N, Figure 12) with surface resistivity of 2 $\mathrm{K} \Omega / \mathrm{Sq}$ was obtained by electroless plating of gold on Film $\mathrm{E}$ (Ag-polymer film at $120^{\circ} \mathrm{C}$ ).

\subsection{Adhesion in Au-Ag-polymer}

Adhesion of $\mathrm{Au}$ with Ag-polymer film was tested by the same method as was used for Ag-polymer film. 
Table 2. Summary of experimental results for synthesis of conductive Au-Ag-polymer film.

\begin{tabular}{|c|c|c|c|c|c|c|c|}
\hline \multicolumn{8}{|c|}{$\begin{array}{l}\text { Flexible Ag-polymer film with strong Ag-PIFlexible Au-Ag-polymer film obtained by electroless Au plating on Film S } \\
\text { adhesion (Film S, Figure 2) } \\
\text { (Film 0, Figure 2) }\end{array}$} \\
\hline SEM & EDS & $\begin{array}{l}\text { Surface } \\
\text { color }\end{array}$ & $\begin{array}{l}\text { Au-Ag-PI } \\
\text { adhesion }\end{array}$ & Conductivity & $\begin{array}{l}\text { Modulus } \\
\text { GPa }\end{array}$ & SEM & EDS \\
\hline $\begin{array}{l}\text { High load of metal } \\
\text { particles (Figure 5) }\end{array}$ & $\begin{array}{l}\text { Sharp peak of } \mathrm{Ag} \\
\text { (Figure 7) }\end{array}$ & Golden & Strong & $\begin{array}{l}\text { Conductive } \\
\text { (Surface resistivity } 2.6 \Omega / \mathrm{Sq} \text { ) }\end{array}$ & 1.46 & $\begin{array}{l}\text { High load of metal } \\
\text { particles (Figure 5) }\end{array}$ & $\begin{array}{l}\text { Sharp peak of Ag } \\
\text { and Au (Figure 7) }\end{array}$ \\
\hline
\end{tabular}
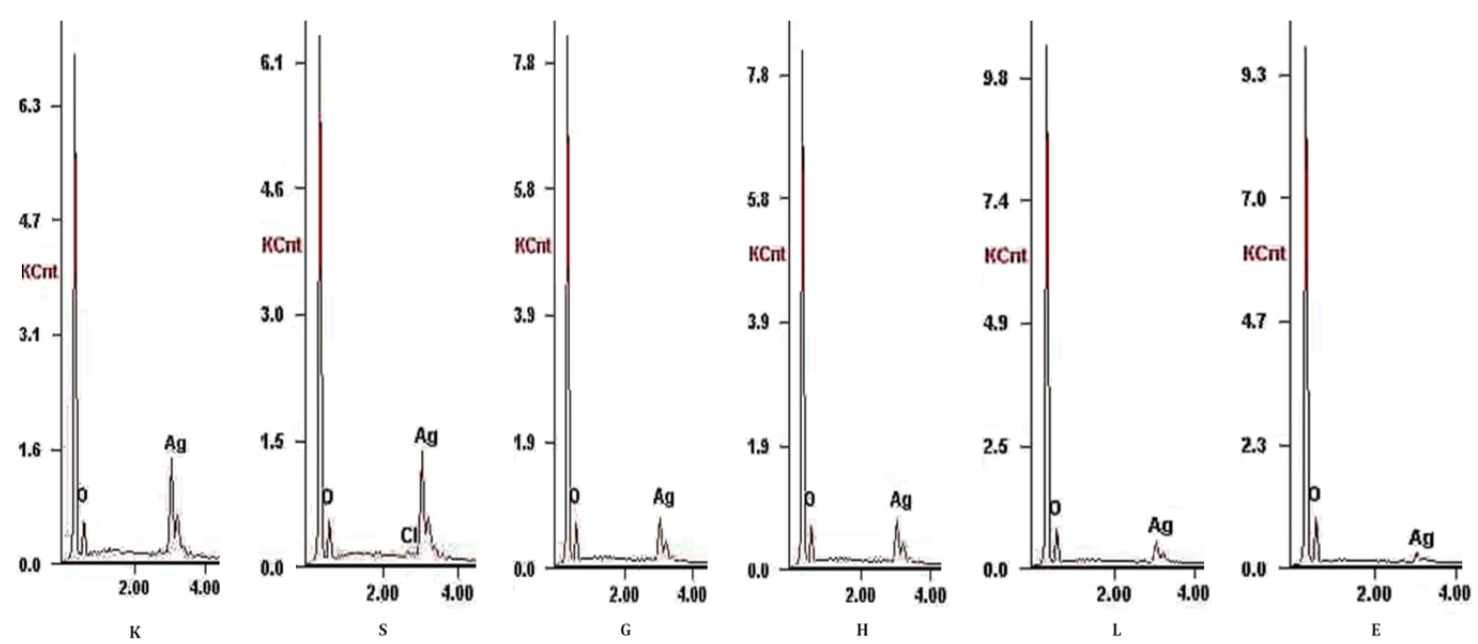

Figure 10. Comparison of EDS of different colored Ag-polymer films: silver colored film (Film K, Film S); golden colored film (Film G, Film H); blue colored film (Film L) and brown colored film (Film E).
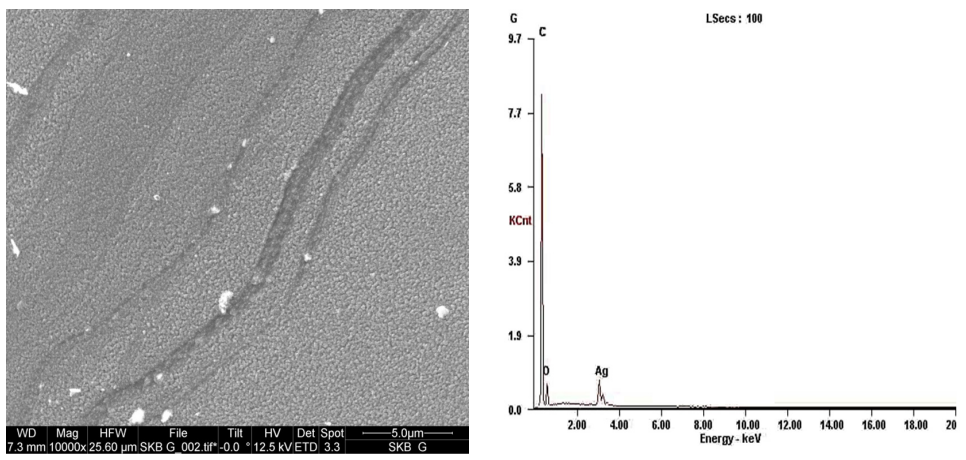

Figure 11. SEM and EDS images of $10 \%$, bright golden colored Ag-polymer film (Film G) obtained at $300{ }^{\circ} \mathrm{C}$ by curing process 2 .

Adhesion was not strong enough in Film N. However, excellent adhesion of Au with Ag-polymer film was found in Film 0. Here, Ag particles in the polymer network worked as active sites for deposition of gold as shown in Figure 13 which, might not be sufficient in Film E (from which Film N was obtained). Ag concentration (reduced silver) in this film was seen very low in EDS (Figure 7) of this film.

\subsection{SEM and EDS of Au plated Ag-polymer film}

Au-Ag-polymer films (Film $\mathrm{N}$ and Film 0) were characterized by SEM and EDS. High load of $\mathrm{Au}$ has been observed in the SEM and EDS images of Film N (Figure S2, supporting information). SEM images of Film 0 in Figure 5, at two different magnifications $10000 \mathrm{X}$ and $40000 \mathrm{X}$, show the presence of metal particles on the Au-Ag-polymer film surface. In Figure 7, EDS shows intense peak of $\mathrm{Au}$ and Ag for this film which proves the presence of high concentration of $A u$ on this $\mathrm{Au}$-Ag-polymer film surface indicating successful plating of gold on the mechanically strong flexible Ag-polymer film (Film S).
In all EDS spectra high $\mathrm{C}$ and 0 ratio was observed. Even in the conductive Au-Ag-polymer film, which seemed almost covered by $\mathrm{Au}$ and $\mathrm{Ag}, \mathrm{C}$ ratio was seen much higher than of $\mathrm{Au}$ and Ag in the film (Film 0). The high carbon ratio can only be explained if it is considered as a contribution from $\mathrm{C}$ used for coating the surface during EDS analysis.

\subsection{Electroactivitity of Ag-polymer film}

Electroactivity of nanostructured film synthesized at low temperature has been checked by cyclic voltammetry on a platinum electrode after depositing Ag-PAA solution $(10 \% \mathrm{Ag})$ on the electrode and heating up to $120^{\circ} \mathrm{C}$. Potential range used for this purpose was $0-1500 \mathrm{mV}$ with a scan rate of $50 \mathrm{mV} / \mathrm{sec}$. $\mathrm{Ag} / \mathrm{AgCl}$ electrode was used as reference electrode. Here initially voltammogram of PAA modified electrode, at the same temperature, has been recorded and then voltammogram of the Ag-PAA modified electrode has been observed. In Figure 14, it is seen that the voltammogram of Ag-PAA modified platinum electrode in PBS buffer shows two oxidation peak at around $245 \mathrm{mV}$ and $515 \mathrm{mV}$ while PAA modified platinum electrode 

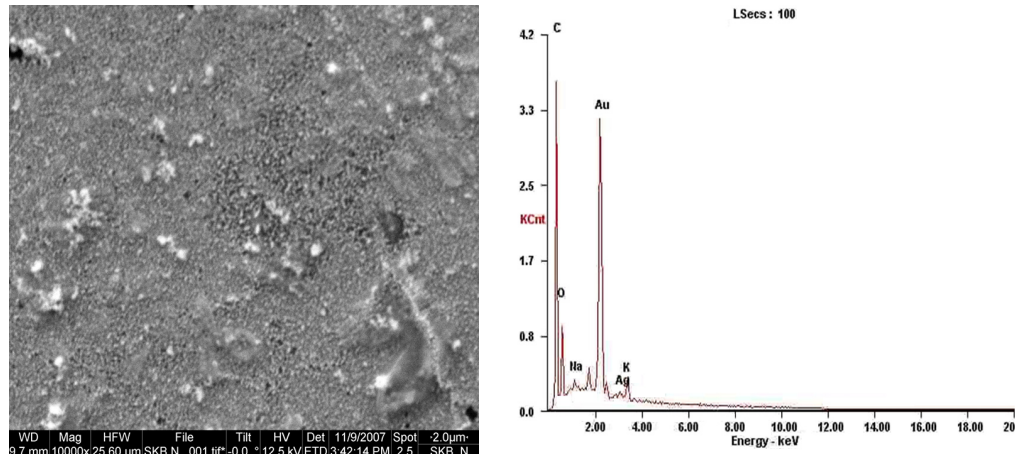

Figure 12. SEM and EDS images of conductive, Au plated Ag-polymer film (Film N) of $120^{\circ} \mathrm{C}(\mathrm{Film} \mathrm{E})$.

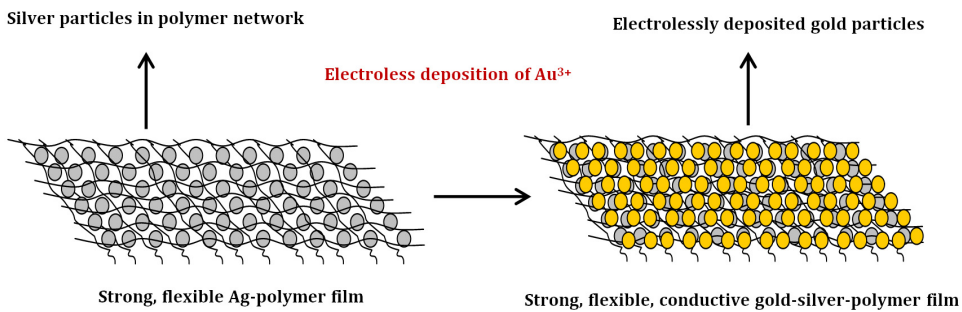

Figure 13. Schematic of electroless deposition of gold on active sites of Ag-polymer film.

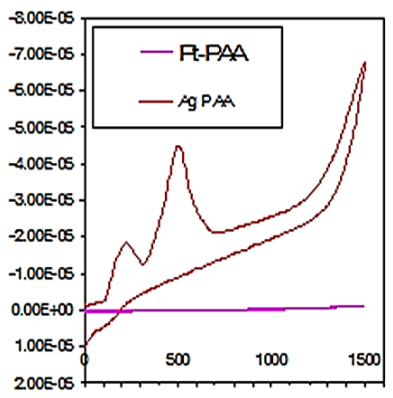

Figure 14. Cyclic voltammogram of polymer modified (-) and $10 \%$ Ag-polymer modified platinum electrodes (-). Here, $x$-axis indicate potential in mV and $y$-axis current in ampere (A). Potential range used was 0-1500 $\mathrm{mV}$ with a scan rate of $50 \mathrm{mV} / \mathrm{sec}$. The voltammogram of Ag-PAA modified platinum electrode shows two oxidation peak at around $245 \mathrm{mV}$ and $515 \mathrm{mV}$ while PAA modified platinum electrode shows no significant peak.

shows no significant peak which confirm the electroactivity of the Ag-polymer film. Here, the calculated electrode potential for Ag oxidation should be near $500 \mathrm{mV}$. So sharp oxidation peak at $515 \mathrm{mV}$ can be denoted for Ag oxidation in the Ag-polymer film on platinum electrode.

\section{Conclusions}

In conclusion, this work reports a simple and effective approach for synthesis of flexible, mechanically strong, nanostructured Ag-polymer film with high $\mathrm{Ag}$ load and excellent Ag-polymer adhesion. In addition, it illustrates a simple, cost-effective synthesis route for synthesis of flexible, mechanically strong, conducting Au-Ag-polymer film with excellent $\mathrm{Au}$-Ag-polymer adhesion. In both cases optimum $\mathrm{Ag}^{+}$ concentration and curing process were determined through studying the qualitative/quantitative effect of metal concentration and curing process on the cured films by a simple onestep method. Low concentration of silver salt and lower rate of increase of temperature during the curing process were found favorable for obtaining nanostructured, mechanically strong, different colored Ag-polymer film whereas high concentration of $\mathrm{Ag}^{+}$favored the formation of silver colored Ag-polymer film with high load of reduced silver. However, high $\mathrm{Ag}^{+}$concentration was found to weaken the mechanical strength of the cured polymer film. Doped Ag particles in the polymer network were utilized as active sites for Au electroless deposition on the strong, flexible Ag-polymer film to obtain conducting polymer film. Strong adhesion of Au with Ag-polymer was only achieved for high load of Ag in the polymer film. The nanostructured film, synthesized in this study, could be an important candidate in nanotechnology for bacterial or bio-warfare treatment. Electroactive nanostructured Ag-polymer film could be used for sensors in environmental monitoring for its protection. This technique for synthesis of conducting Au-Ag-polymer film could lead us to successful printing of electronic circuits on polymers for flexible electronics. Controlling size and concentration of different metal nanoparticles in flexible and mechanically strong polymer films and successful applications of the synthesized films will be investigated extensively in future research. In synthesis of noble nanostructured and conducting polymer films for practical applications, the research, discussed here, could find considerable importance in terms of cost, efficacy and simplicity. 


\section{Acknowledgements}

The author expresses her sincere thanks to the integrated electronics engineering center (IEEC), and U.S. EPA for supporting this work and to State University of New York at Binghamton for giving her the opportunity to perform this research. She acknowledges Kenneth M. Bart of Hamilton College for SEM and EDS analysis of the synthesized films and thanks those who supported this work by generous help in different ways. She thanks the University of Chittagong, Bangladesh for granting her leave to accomplish this report.

\section{References}

[1]. Strunskus, T.; Grunze, M.; Kochendoerfer, G.; Ch-Woll. W. Langmuir 1996, 12, 2712-2725.

[2]. Siegel, J.; Kotal, V. Acta Polytechnica 2007, 47, 9-11.

[3]. Xi-Shu, W.; Hua-Ping, T.; Xu-Dong, Li; Xin, H. Int. J. Mol. Sci. 2009, 10, 5257-5284.

[4]. Rubira, A. F.; Rancourt, J. D.; Caplan, M. L.; Clair, A. K. St.; Taylor, L. T. Chem. Mater. 1994, 6, 2351-2358.

[5]. Pi-Jiun, L.; Mao-Chieh C. Jpn. J. Appl. Phys. 1999, 38, 4863-4866.

[6]. Pfluger, S.; Wehner, M.; Jansen, F.; Kruck, T.; Lupp, F. Appl. Surf. Sci. 1995, 86, 504-508.

[7]. Southward, R. E.; Thompson, D. S.; Thompson, D. W.; Clair, A. K. St. Chem. Mater. 1999, 11, 501-507.

[8]. Southward, R. E.; Thompson, D. W. Mater. Des. 2001, 22(7), 565-575.

[9]. Qi, S.; Wang, W.; Wu, D.; Wu, Z; Jin, R. Eur. Polym. J. 2006, 42, 20232030.

[10]. Qi, S.; Wu, Z;; Wu, D.; Wang, W.; Jin, R. Chem. Mater. 2007, 19(3), 393401.

[11]. Kim, J.; You, J.; Kim, E. Macromolecules 2010, 43(5), 2322-2327.

[12]. Guo, S.; Dong, S. J. Mater. Chem. 2011, 21, 16704-16716.

[13]. Hu, L.; Wu, H.; Cui, Y. MRS Bull. 2011, 36, 760-765.

[14]. Jensen, T.; Kelly, L.; Lazarides, A.; Schatz, G. C. J. Cluster Sci. 1999, 10, 295-317.

[15]. Doria, G.; Conde, J.; Veigas, B.; Giestas, L.; Almeida, C.; Assuncao, M.; Rosa, J.; Baptista, P. V. Sensors 2012, 12, 1657-1687.

[16]. Conde, J.; Doria, G.; Baptista, P. J. Drug. Deliv. 2012, Article ID 751075, 12 pages.

[17]. Balazs, A. C.; Emrick, T.; Russel, T. P. Science 2006, 314, 1107-1110.

[18]. Usuki, A.; Kojima, M.; Fukushima, Y.; Kamigaito, O. J. Mater. Res. 1993, $8,1179-1184$.

[19]. Polonskyi, O.; Solar, P.; Kylian, O.; Drabik, M.; Artemenko, A.; Kousal, J.; Hanus, J.; Pesick, J.; Matolinova, I.; Kolibalova, E.; Slavínska, D.; Biederman, H. Thin Solid Films 2012, 520, 4155-4162.

[20]. Pillalamarri, S. K.; Blum, F. D.; Tokuhiro, A. T.; Bertino, M. F. Chem. Mater. 2005, 17, 5941-5944.

[21]. Xing, S.; Zhao, G. Mater. Lett. 2007, 61, 2040-2044.

[22]. Wang, Y.; Li, Y.; Sun, G.; Zhang, G.; Liu, H.; Du, J.; Yang, S.; Bai, J.; Yang, Q. J. Appl. Polym. Sci. 2007, 105(6), 3618-3622.

[23]. Balan, L.; Burget, D. Eur. Polym. J. 2006, 42, 3180-3189.

[24]. Liu, C.; Yu, X. Nanoscale Res. Lett. 2011, 6, 75-82.

[25]. Madaria, A. R.; Kumar, A.; Zhou, C. Nanotechnology 2011, 22(24), 245201-245207.

[26]. Byrne, M. T.; Gunko, Y. K. Adv. Mater. 2009, 22(15), 1672-1688.

[27]. Andrews, R.; Weisenberger, M. C. Curr. Opin. Solid State Mater. Sci. 2004, 8, 31-37.

[28]. Al-Saleh, M. H.; Sundararaj, U. Carbon 2009, 47, 2-22.

[29]. Hu, X.; Dong, S. J. Mater. Chem. 2008, 18, 1279-1295.

[30]. Luo, X.; Morrin, A.; Killard, A. J.; Smyth, M. R. Electroanalysis 2006, 18(4), 319-326.

[31]. Otsuka, H.; Nagasaki, Y.; Kataoka, K. Adv. Drug. Deliv. Rev. 2003, 55, 403-419.

[32]. Sondi, I.; Salopek-Sondi, B. J. Colloid Interface Sci. 2004, 275, 177-182.

[33]. Lee, D.; Cohen, R. E.; Rubner, M. F. Langmuir 2005, 21(21), 9651-9659.

[34]. Aslan, K.; Baillie, L. W.; Geddes, C. D. J. Med CBR Def. 2010, 8.1-21

[35]. Kim, J. S.; Kuk, E.; Yu, K. N.; Kim, J. H.; Park, S. J.; Lee, H. J.; Kim, S. H.; Park, Y. K.; Park, Y. H.; Wang, C. Y.; Kim, Y. K.; Lee, Y. S.; Jeong, D. H.; Cho, M. H. Nanomedicine: NBM. 2007, 3, 95-101.

[36]. Clement, J. L.; Jarrett, P. S. Met.-Based Drugs 1994, 1, 467-482.

[37]. Akamatsu, K.; Tsuboi, N.; Hatakenaka, Y.; Deki, S. J. Phys. Chem. B 2000, 104, 10168-10173.

[38]. Li, Y.; Lu, Q.; Qian, X.; Zhu, Z.; Yin, J. Appl. Surf. Sci. J. 2004, 233(1-4), 299-306.

[39]. Xiaohong, L.; Wang, J:; Zhang, J.; Liu, B.; Zhou, J.; Yang, S. Thin Solid Films 2007, 515, 7870-7875.

[40]. Deng, Y.; Dang, G.; Zhou, H.; Rao, X.; Chen, C. Mater. Lett. 2008, 62, $1143-1146$

[41]. Frankenthal R. P.; Becker, W. H. J. Electrochem. Soc. 1979, 126, 17181719.

[42]. Okinaka, Y. Plating 1970, 57, 914-920.
[43]. Gaudiello, J. G. IEEE Trans. Compon. Packag. Manuf. Technol. Part A 1996, 19, 41-44.

[44]. Jing-Ying, L; Xiu-Li, X; Wen-Quan, L. Waste Manage. 2012, 32, 12091212.

[45]. Yoon, S. S.; Kim, D. O.; Parka, S. C.; Lee, Y. K.; Chae, H. Y.; Jung, S. B.; Nam, J. D. Microelectron. Eng. 2008, 85, 136-142.

[46]. Takekoshi, T. Adv. Polym. Sci. 1990, 94, 1-25.

[47]. Sheng, Q. G.; Zhang, Yi. L.; Jia, Z. L.; Yang, S. Y. High Perform. Polym. 1999, $11,167-173$.

[48]. Alexander, A.; Tsegelskaya, A. U.; Buzin, P. V.; Yablokava, M. Y. High Perform. Polym. 2007, 19, 711-721.

[49]. Bergmeister, J. J.; Taylor, L. T. Chem. Muter. 1992, 4, 729-737.

[50]. Madeline, D. G.; Spillane, S. A. Taylor, L. T. J. Vac. Sci. Technol. 1987, A5, 347-353.

[51]. Rancourt, J. D.; Taylor, L. T. Macromolecules 1987, 20, 790-795

[52]. Eustis, S.; El-Sayed, M. A. Chem. Soc. Rev. 2006, 35, 209-217. 